social organization we can never know, nor can we guess what acceleration the future may bring to it if more of the best minds are set free within the state for work of this highest kind, what riches may be added to intellectual life, or what fuller service may be given to the practical affairs of man and to the merciful work of medicine.

\section{WALter Fletcher}

\section{TETRACHROMATIC VISION AND THE DEVELOPMENT THEORY OF COLOR}

IT would seem to be time for the poor children in the kindergarten to be taught that the number of different "colors" in the spectrum (and in the whole world of natural objects as well) is not seven, nor six, but simply four -red, yellow, green and blue. We have been told lately by Dr. Jennings, in the American Journal of Physiological Optics, that the number is seven, and by U. S. Public Health Bulletin No. 92 (prepared by direction of the Surgeon General) that the number is six. The Milton Bradley Company, which furnishes countless delightful kindergarten objects for the children, follows the customary delusion that there are six. But every psychologist knows by this time, thanks to the life-long labors of Hering, that the number of different chromatic sensations (chromata) furnished by the spectrum, and by all of nature too, is four. No physicist, however, is as yet aware that there are more than three; I am in the habit of saying that the physicists are all psychically blind to both yellow and white, all save one, Professor Robert Wood, who in his Physical Optics explicity recognizes the existence of a "subjective" yellow. In course of time, no doubt, even the physicists will recognize the fact that all the color sensations are "subjective"-that there are no reds, greens, etc., in the extra-corporeal world, but that there are simply the erythrogenic, xanthogenic, chlorogenic and cyanogenic light rays-and that any ray-combination that looks white (as, for instance, a mixture of "yellow" and "blue" light) is a leucogenic combination and due to a "leuco-base."
The reason that led Newton to find seven colors in the spectrum was an æsthetic onethe spectrum is, counted in wave-lengths, about an octave long; in the music octave we recognize seven notes, so why not assign seven tones also to the color octave? In this way what was common knowledge in regard to the number of colors in the world from the time of Leonardo da Vinci became vitiated for a hundred and fifty years by an error which it is still hard to recover from. Hering, in opposition to Helmholtz, recognized that there are four chromatic sensations, but he too was led astray by a logico-aesthetic consideration; he thought it would be nice if, since red and green are, like blue and yellow, a "disappearing" color pair, they were also a white-constitutive color pair. So he said we will assume that they are a white-constitutive color pair, and to make the situation still more pleasing we will assume that black and white too are at least a disappearing color pair. But I have shown that when you take the exact red and green (or, in fact, anything near them) you get, on mixing, not white but yellow. My contention on this point has been accepted by Westphal, by v. Kries and others; the colors which are complementary, or white-constitutive, are, as Titchener, with a degree of honesty which is unusual in the followers of Hering, admits, not red and green, but crimson and verdigris,-in other words, white is here, as elsewhere, made out of red, green and blue.

Normal, mid-retinal, vision is tetrachromatic. It is to be hoped that we may sometime persuade the Milton Bradley people (whose red, green, yellow and blue papers are, as I have shown, very near to the exact, unitary, Red, Green, Yellow and Blue-I write these colornames with capitals when the colors are exact), and the United States government as well, that the different colors in the spectrum are four in number, and that if one adds to one's papers two of the dual color-blends, red-blue and redyellow (the so-called purple and orange), one should add also the remaining dual color-blends, green-blue and green-yellow. (The fact that these last two color-blends have no misleading unitary names is so much to the good). At- 
tention should be called at the same time to the curious fact that though you may easily have the physical conditions (the proper light-ray mixtures) for the two other possible dual colorblends (the red-greens and the yellow-blues), these are sensations that never occur-their places are taken, respectively, by yellow and by white.

I should like to mention that the color theory which I have proposed (the development color theory) is the only one in existence which holds together (the function of a theory), and makes reasonable, the three fundamental color-sensation facts (and the other, subsidiary, facts as well). These are:

A. The Helmholtz fact: the basis of colorvision is a three-receptor (chemical) process, -the "red," "green" and "blue" light-rays are sufficient (on mixing) to reproduce the whole gamut of the color sensations.

B. Nevertheless (the Hering fact) yellow and white are also unitary sensations and not any sort of sensational color blends, although they may be produced by physical light-ray mixtures. Hering thus corrects what I have called the psychical color-blindness (to yellow and to white) of the Helmholtz school, but at the cost of concealing from his followers all the facts which are mapped out in the Helmholtz triangle, or what the metallographers call when they make a diagram of their ternary alloysa less frightening word perhaps-the "triaxial diagram." The color-triangle, in other words, is nothing more than the representation of mixed color-constitution in terms of trilinear coordinates; what could be more natural when the variables which are both sufficient and indispensable are three in number?

C. Of equal importance is the fact of the order of phylogenetic development of the lightsensations (achromatic and chromatic). It is, in its three successive stages, as has been perfectly well made out, this :

(1) A white-sense only, achromatic vision (furnished by the more primitive retinal elements, the rods), which occurs $(a)$ in the lower animals, such as lived, for instance, in carboniferous times (when colored flowers and colored birds did not yet exist $)^{1},(b)$ in those defective individuals who have achromatic vision only, and $(c)$ in the far periphery of our own retina.

(2) Dichromatic vision-the spectrum is yellow at one end, blue at the other (but in place of what should be the yellow-blues appears white). This is the vision $(a)$ of the bees (v. Frisch), (b) of the partially color-blind, and $(c)$ of our own mid-periphery.

(3) Complete, tetrachromatic, color-vision, - the red and green sensations have been added; but where we have the physical conditions for seeing the red-greens, or the red-green-blues, yellow and white, respectively, take their places.

The theory of Helmholtz is (as Professor Cattell has well said) both pre-psychological and pre-evolutionary. That of Hering (besides being otherwise impossible) is pre-evolutionary: there is no question that red and green (which revert to yellow) are developed out of yellow. But worse than this-each of these theories is utterly contradictory to the facts which the other theory is expressly built up upon. This circumstance has not hitherto been sufficiently noticed; this Mr. Troland says ("The Enigma of Color Vision," American Optical Society, p. 8): "The YoungHelmholtz theory is preferred by physicists because it lays emphasis primarily upon the stimuli to vision, while the Hering theory receives more attention at the hands of the psychologists because its fundamental conceptions are derived from introspective analysis." This is true, but it is very far from being an adequate account of the situation. (1) The Young-Helmholtz school not only assumes but proves (not, as is often said, by means of the König-Dieterici spectral distribution curves by themselves, but by the complete coincidence of these curves with those, respectively, of the

1 We have no means of knowing whether our own background sensation, the non-light sensation, that of blackness (which exists for the purpose of filling up our visual field), came in with the first, non-specific, light-sensations, or only later: There is some ground for thinking it arose later. I discuss this question in my coming article on "The Sensation of Blackness." 


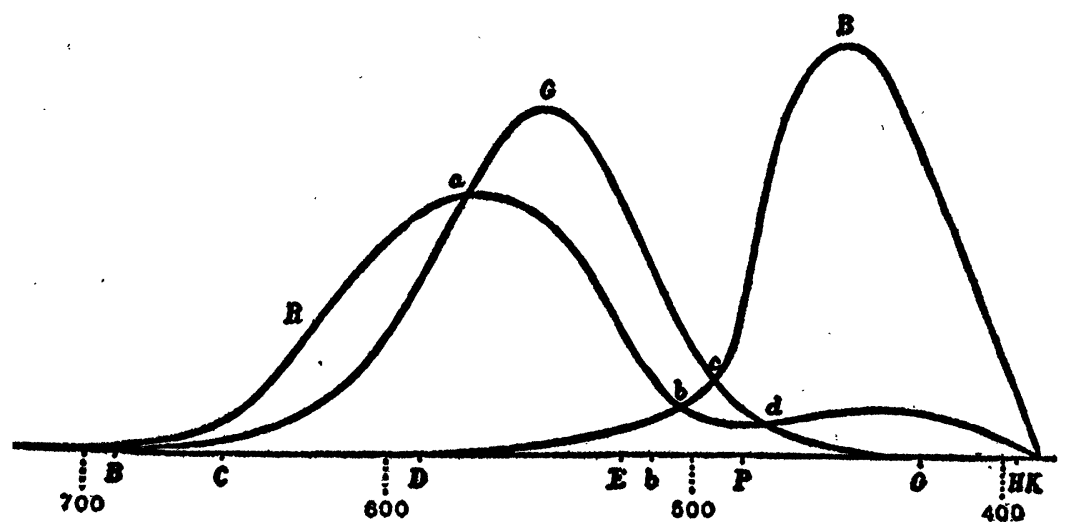

Fig. 1. $R, G$, and $B$, resonance curves. These are the curves of König and Dieterici corrected to new determinations of the points of section, $a, b, c, d$. Abscissæ, wave-lengths of the interference spectrum of the are light; ordinates, arbitrary scale. (F. Exner.)

two types of yellow-and-blue vision $)^{2}$ that the number of "primary" colors is three and not four. (Fig. 1). This is fact. (2) The Hering school has only to ask for the most cursory examination of the gamut of color-sensations to show that the number of its different chromatic constituents is four, not three. This is fact. But the group of facts subsumed under (1)the facts of "matehing by mixture" (Fig. 2)is absolutely incompatible with the theory of Hering, ${ }^{3}$ and the group of facts subsumed under (2) is absolutely incompatible with the theory of Helmholtz. It is little to the credit of any association of scientists (for instance, the Optical Society of America) that they still solemnly discuss the theories of Helmholtz and of Hering. The situation is simple: each of these theories is absolutely refuted by the facts which are the groundwork of the other.

I have devised a simple diagram by means of which one ean keep in mind the impossibility at once of the Helmholtz and of the Hering

2 Dictionary of Philosophy and Psychology, Art Vision, II, 788.

3 The attempt of $v$. Kries to supplement the Helmholtz theory by supposing that the three colors resolve themselves into four at a higher level of the visual nerve system is a purely ad hoc hypotheses, and without significance. See my articles on "The Theory of Color Theories," Comptes rendus du V/e Congrès, intern. de Psychologie, Genève, 1909, and Psychological Review, May, 1922. theory. Color diagrams are immensely more illuminating if they are done up in color. ${ }^{4}$ But lacking that one can make shift with appropriately striated surfaces. I call this diagram my Quadrigeminal Color Body (a term suggested by the corpora quadrigemina), but it is at the same time triaxial. (The triangle should always be drawn with the YB line a horizontal (fundamental) line, as indicative of the fact that yellow and blue were developed first-that red and green were a later addition. (The actual spectral line approaches nearer to the point $\mathrm{W}$ in the green region on

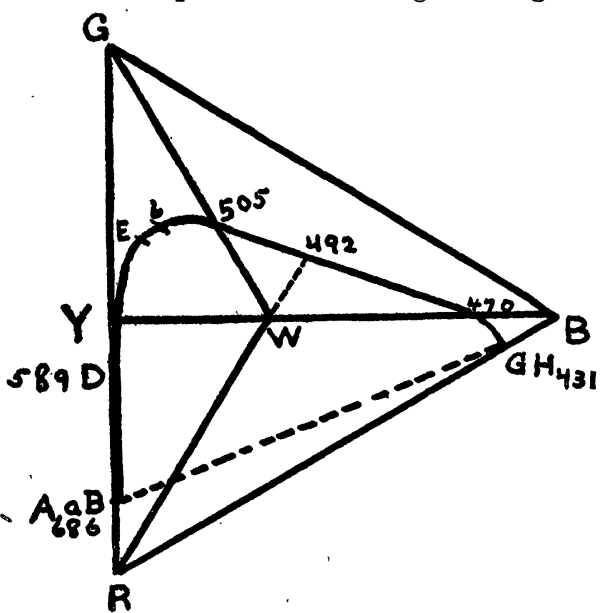

FIG. 2. The color triangle, which exhibits "matching by mixture.",

4 Stoelting is putting on the market for me my complete' set of colored color diagrams. 
account of the fact that the three chroma ${ }^{5}$ curves overlap here, as is represented in Figure 1).

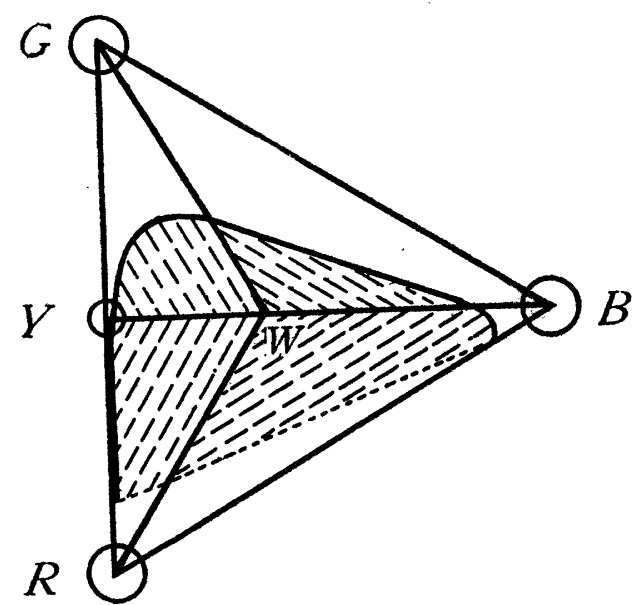

FIG. 3. The quadrigeminal color area-triangular in shape.

This. figure illustrates the fact that while the color field is a function of three variables when you reproduce it by the mixing of specific lights, you no sooner look at it than you see that it consists of four distinct regions-the whitish yellow greens, the reddish bluish whites, ete. It suffices to upset at once the two "antj.. quated" (as they call them at the University of Chicago) current theories. I make the yellow circle small to indicate $(a)$ that yellow occupies a very narrow region in the spectrum, (b) that it is the result of a secondary retinal process, and $(c)$ that it has been for a hundred years invisible to the physicists. It is this color curve, representing facts and not imaginations (like the color-curves of Hering), which should, of course, always be drawn as the belt-section of the color-pyramid.

To meet the difficulties of these antiquated theories I have devised a theory (the development theory) "which takes into account both sets of fundamental facts which the other theories were respectively devised to explain," facts which do however in reality collectively refute them both. (You will not find even a picture

5 I have been constantly urging, since 1913, the use of the word chroma (plural, chromata) to obviate the shocking ambiguity in the present meaning of "color." of the color triangle in any of the writings of the followers of Hering). It is a perfectly simple theory (the theory of Hering is far from simple-see Parsons, p. 673), and it is wholly in line with the most recent conceptions of the chemists-Harkins, Bohr, Soddy, Rutherford (who are now engaged in working out the evolution of the atoms), Mathews, Willstäuer (chlorophyll and hæmoglobin, Bayliss, p. 252) and many others. This theory has been pronounced to be unobjectionable by the chemists, and it is now practically accepted by most of the psychologists.

The theory in brief is this:

There is probably no other organ in the body in which the record of development has been preserved in such a remarkable fashion as in the organ of vision. We have, pari passu with the successive stages of specificity of response to the visual spectrum, represented in Fig. 3,

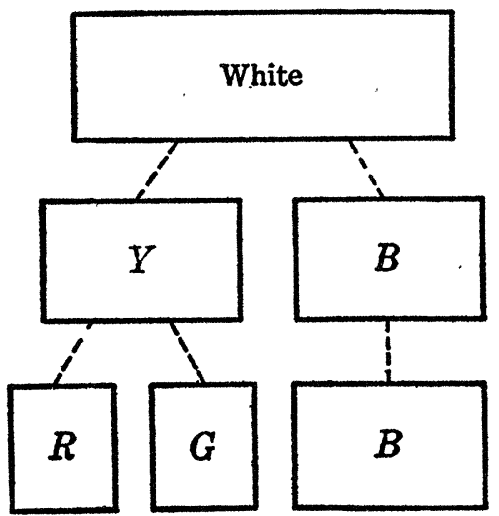

FIG. 4. Stages 1, 2 and 3 of the actual development of the color sense.

(1) an anatomical development of rods into cones, and (2) a chemical development of the rod-pigment sensitizer such that in man only there is an intermediate stage, the visual yellow, between the "visual purple" and the final leuco-base (König, Garten). What more natural than to suppose that there has been also a development of the light-sensitive receptor substance in the receptor organs (rods and cones) of the retina? This developing substance must, however, be at the same time of such a nature as to account for the singular fact (unknown in any other region of sense) that the colors successively developed are dis- 
appearing color pairs-they produce a more primitive white, or yellow (see above). If these facts are held distinetly in mind, the appropriate chemical conception almost forms itself. I represent, purely diagrammatically, of course (Burdon-Sanderson ${ }^{6}$ especially noted this point when my theory first came out) that portion of a molecule which is capable of being dissociated out of light in the way indicated in Figure 4.

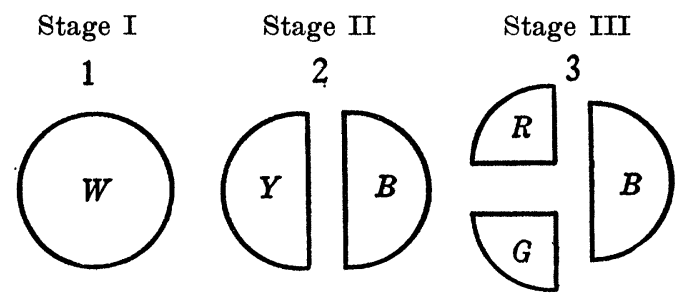

FIG. 5. The cleavage products in the three stages of the color sense. This diagram does not represent the entire light-sensitive molecule, but only the specific cleavage products which, according to the Ladd-Franklin theory, constitute the several nerve excitants for the color sensations (From Woodworth's Psychology). For other diagrams, see Psychological Review, 23: 247, 1916; Zeitschrift f. Psychologie, Bd. 6, etc.

The development required is that of a greater and greater specificity to the electro-magnetic vibrations of the visible spectrum. A portion of a molecule which at first is broken off indifferently by the whole spectrum becomes in a second stage more specific,- by a fresh aggregation of atoms a portion $Y$ responds to the yellow end of the spectrum, a portion $B$ to the blue end of the spectrum. But what happens when yellow and blue light fall at once on this chemical substance? The $Y$ and the $B$ (since they are the ehemical constituents of $W$, because the assumption is that they were segregated out of it) will chemically unite and will produce $W$, the nerve-excitant of the sensation white. In the same way in the third, and latest, stage, the newly segregated $R$ and $G$, when torn off from the molecule by light of low and of high middle frequency, will revert to the mother substance $Y$; and if light of high frequency, "blue," is now added, we shall again have the nerve-excitant of white. That is to say, just as when we have in a test-tube the

\footnotetext{
6 Presidential Address, British Association, Nature, Vol. 48, p. 469.
}

chemical constituents of $\mathrm{HCl}$ (namely, $\mathrm{H}$ and $\mathrm{Cl})$ they chemically unite, under proper conditions, and produce $\mathrm{HCl}$, so in a cone we have

$$
R+G=\frac{F}{Y+B}(=R+G+B)=W
$$

Observe that we have now, quite incidentally, explained how it happens that lights of only three specific, homogeneous wave-lengths ("red," "green" and "blue") are sufficient to reproduce the whole gamut of color sensations, including yellow and white, which the psysicists have never noticed the existence of. ${ }^{7}$ Yellow is a secondary product, and so is white, but they are both perfectly good unitary sensations. The theory explains at the same time, of course, how it is that the primitive white mediated by the rods is the same sensation as the white made out of (in the highly developed cones) yellow and blue, or red and green and blue. There is no reason, of course, as Professor Carr has pointed out to me, why there should not be also some of the more primitive chemical substances in the cones of the central retina.

Since the interesting work of Hecht, it seems to be quite certain that the first effect of light on the retina is photo-chemical (which is, of course, the same thing as electrical). It is here, without question, that is found that "transformer mechanism," as I have called it, by which what should look to us like 165 different colors in the spectrum is replaced by a paltry four-the best that Nature could accomplish with only one small cone to work in. Five unitary colors (including white) and mixtures of them-the color blends-are all that we can see in the 30,000 discriminable sensations that are given us by light. It is nerve impulses produced by retinal chemical stimuli of the character which I have described (or of some other character) that mediate the processes which take part in the final "neuro-

7 Crowther, a prominent English physicist, actually says that the white produced by mixing homogeneous yellow and blue light-rays is not a "real" white-that, he thinks, must be a wholespectrum white. Professor Titchener, on the other hand, has called my attention to the fact that on my view white is always (aside from the most primitive stage) due to a union of yellow and blue constituents. 
psychic correlation"-a term which I have proposed as much preferable to psychophysical parallelism-in the domain of color.

In a recent discussion of my color theory (Am. J. Physiol. Optics, 1920-21) it is maintained that it would be more "advanced" to regard as of "prime importance" the cortical processes: "It appears to me that the LaddFranklin theory postulates the existence in the retina of conditions of sensation of the sort required for the processes in the cerebral cortex which directly underlie the visual consciousness, but which are not required and probably do not exist in the case of the retina." In reply to this it is only necessary to point out that if a "mechanism of defect" (such as would result in loss of consciousness for the redgreens and the yellow-blues) is found to occur in any part of the light-sensation chain (rods and cones, bipolar cells, third neurons, corpora quadrigemina, optic thalamus, cortex) that defect cannot be recovered from in any one of the later stations of the nerve impulse-if $R$ and $G$ have once reverted into $Y$, and $Y$ and $B$ into $W$, anywhere in the visual circuit, it is not necessary to provide for their doing it again in the cortex; on the other hand, if this defect has not happened lower down-if a separate "blue" and "yellow" have successfully reached the cortex-it is improbable that Nature, out of pure Bösartigkeit, should have introduced in the cortex a mechanism for their extinction. ${ }^{8}$

v. Kries has objected that in my theory it is not explained how the same sensation of whiteness should be mediated directly in the rods and in the more highly developed cones out of a physical mixture of red, green, and blue lights, but, as I have pointed out above, this is exactly what my theory does explain.

It has been called to my attention that several of the psychologists, while practically adopting my theory of color sensation, express the opinion that I have given no explanation of the sensation of black. But that is not the case; I have not, it is true, discussed black very frequently, and that, I believe, for two reasons. (1) It is very simple-it has no connections with any other of the color-sensations.

$8 \mathrm{I}$ discuss this point more fully in the Psychological Review, May, 1922.
The reason that color "theory" is so important, and has been so contended over, is that the facts of color (excluding black) are so very mysterious: why do we fail to see the yellowblues and the red-greens, and why do we get, respectively, white and yellow in their place? Blackness stands by itself-it has no such queer relations with any of the other colors. Black and white, for instance, are not a disappearing color pair; they give us the series of black-whites, or greys. Black, being a sensation attached to zero stimulation-not a light sensation but a non-light sensation-is natarally (since zero has one value only) a sensation of only one degree of subjective intensity; the series of greys comes from changing the subjective intensity of their white constituent only. A blue-green of a given proportion of blueness and greenness we can see in dozens of different intensities; not so a grey. Give a certain grey a higher illumination and you change the quality as well as the brightness of your black-white blend. Professor G. E. Müller has dwelt upon this latter fact, but he has given a wrong interpretation of it; Wundt also, although his theory of color is negligible (and has been neglected), puts this situation correctly. It is easily accounted for on my theory.

A fuller account of the Development Theory of Color Sensation will be found in most of the recent books on psiychology, - as Calkins, Judd, Angell, Breese, Watson, Warren and Woodworth. I have discussed it also in the Psychological Review, 23, 1916, and 29, 1922; in the Am. Cyclop. of Ophthalmology, 1913; in the Dictionary of Philosophy and Psychology; in Mind, 1892, 1893, and in ScIence, 22, pp. 18-19. In the last two places I have discussed its fundamental difference from the theory of Donders. My theory has been taken over by Schenck without due acknowledgment, as has been pointed out for me by v. Brücke (Zentrlbl. f. Physiologie, 1905). It has suffered from not having been criticised enough; some critieism of it by v. Kries and by Troland I have discussed very fully in Practical Logic and Color Theories (Psychological Review, May, 1922).

Christine Ladd-FrankLin

Columbia UNIVERSITY 